\title{
CORRECTION
}

\section{Correction to: Changes of microorganism composition in fresh and stored bee pollen from Southern Germany}

\author{
Carolin Friedle $^{1,2}\left(\right.$ Paul D'Alvise $^{2} \cdot$ Karsten Schweikert $^{3} \cdot$ Klaus Wallner $^{1} \cdot$ Martin Hasselmann $^{2}$
}

Published online: 22 December 2021

○) Springer-Verlag GmbH Germany, part of Springer Nature 2021

Correction to: Environmental Science and Pollution Research (2021) 28:47251-47261

https://doi.org/10.1007/s11356-021-13932-4

The image of Figure 1 is corrupted in the published online version. Correct image is shown in this paper

The Original article has been corrected.

Publisher's Note Springer Nature remains neutral with regard to jurisdictional claims in published maps and institutional affiliations.

The original article can be found online at https://doi.org/10.1007/ s11356-021-13932-4.

Carolin Friedle

carolin_friedle@uni-hohenheim.de

1 Apicultural State Institute, University of Hohenheim, Stuttgart, Germany

2 Institute of Animal Science, Department of Livestock Population Genomics, University of Hohenheim, Stuttgart, Germany

3 Core Facility Hohenheim and Institute of Economics, University of Hohenheim, Stuttgart, Germany 
Fig. 1 Stack bar chart, showing the composition of bacterial (a) and fungal (b) communities of Dataset 2 (F and N 2019) (filtered on minimum of $10 \%$ average) in fresh and stored bee pollen

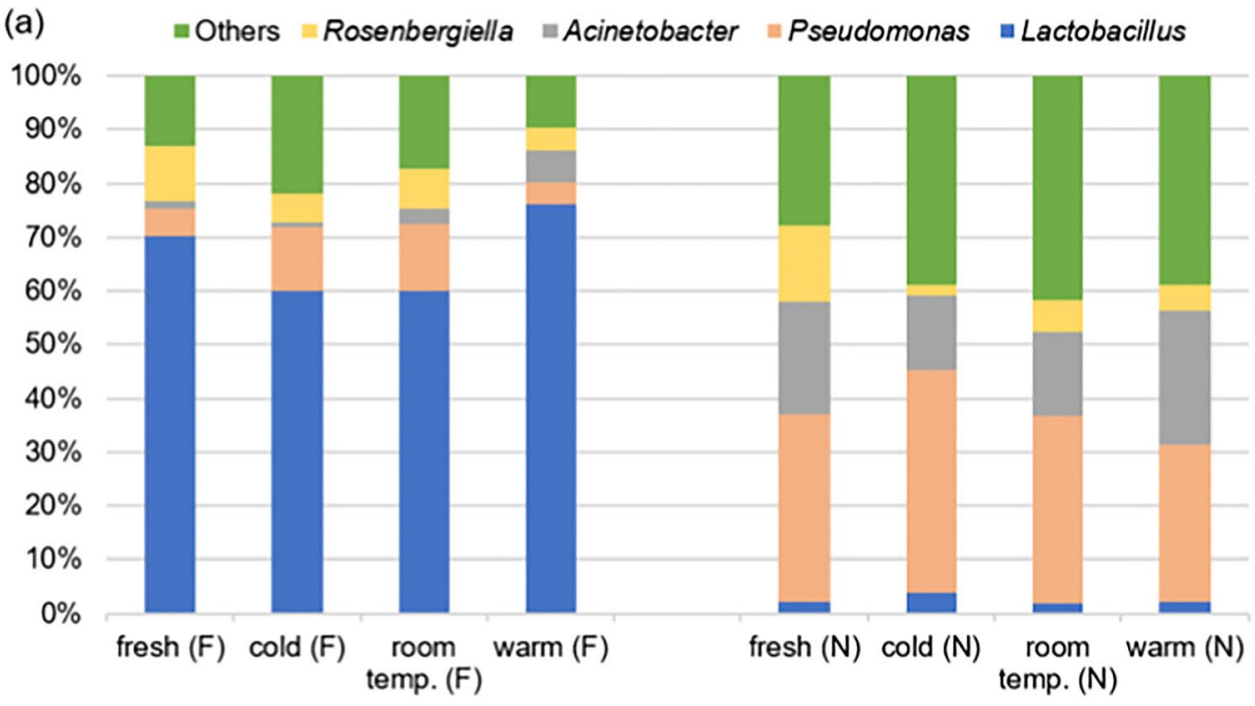

(b)

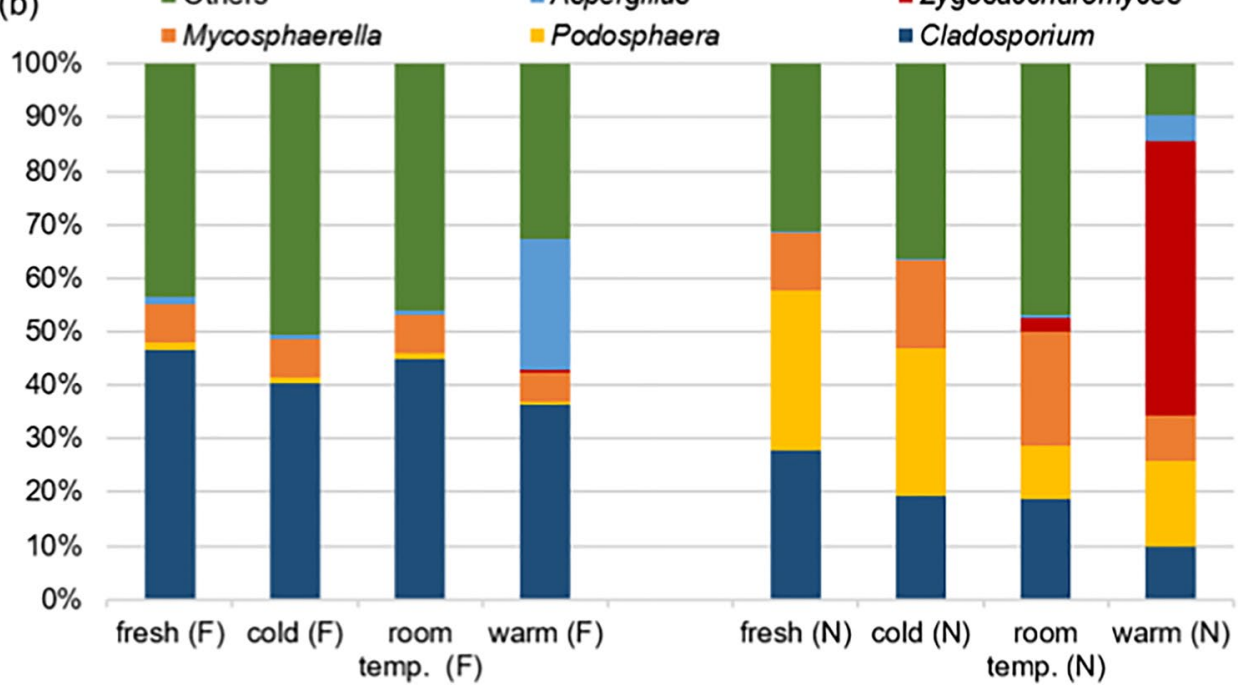

